\title{
Time-averaged single sided ventilation rates and thermal environment in cooling mode for a low energy retrofit envelope system
}

\author{
Paul D O’Sullivan ${ }^{1,2}$, Maria Kolokotroni ${ }^{2}$ \\ ${ }^{1}$ Cork Institute of Technology, Rossa Avenue, Bishopstown, Cork, Ireland \\ ${ }^{2}$ Brunel University, Uxbridge UB8 3PH, United Kingdom
}

\begin{abstract}
Non-invasive, scalable, building retrofit solutions are very attractive deep renovation techniques to improve energy efficiency in existing buildings; this includes natural ventilation for cooling due to the low impact nature of the installation. However, a number of criteria that are important to natural ventilative cooling strategies can be substantially altered as a result of an external retrofit solution. This paper investigates this experimentally; it presents ventilation rate and internal thermal environment results from full scale testing of a modular, scalable, external low energy retrofit envelope solution applied to an existing 1970s precast concrete building in Ireland. Experimental results of time averaged single sided ventilation rates for three different ventilation opening configurations in a retrofitted office space during a warm and low wind summer period are analysed and compared to a single configuration control space. Results show that the highest time averaged ventilation rates were measured in the control space although a similar distribution was present in one retrofit opening configuration. Analysis of tracer concentration decay fluctuation profiles during tests suggest increased unsteady flow effects in the control space compared to all retrofit configurations. This is likely due to the different responses to turbulent diffusion processes and wind pressure fluctuations at the window opening compared to the louvred retrofit design. Zone thermal stratification and diurnal temperature variation within the control and retrofit spaces were measured during each ventilation rate test and also continuously for an extended period. Results show that vertical temperature differences have been substantially reduced following the retrofit works with all $\Delta T_{s}$ values within recommended acceptable limits.
\end{abstract}

Keywords: tracer decay tests, single sided ventilation rate, envelope retro-fit, stratification factor

\section{INTRODUCTION}

Ventilative cooling coupled with exposed thermal mass is widely accepted as an important strategy for reducing summer overheating in non-domestic buildings. Extended monitoring has shown that naturally ventilated buildings typically use less than $50 \%$ of the corresponding energy consumption of air conditioned buildings and assessment of ventilative cooling techniques in Europe have shown they may contribute highly to reducing the cooling needs of buildings (Kolokotroni et al 1996, 2008) and be an effective tool for tackling climate change adaptation in existing buildings. Furthermore, increased ventilation rates can also lead to improved work performance (Seppanen et al. 2006). Recently, focus for market activation in the construction sector has shifted towards dealing with the overhaul of the existing building stock. Article 9 of the EPBD (European Union 2012) brings in refurbished buildings under the near zero-energy umbrella by requiring member states to develop policies in order to stimulate the transformation of refurbished buildings into near zero-energy buildings (NZEB). The Irish National Energy Efficiency Action Plan 2013-2020 (DCENR 2013) report has identified refurbishment of existing public sector buildings as a key focus. The report states that there are over 10,000 existing public sector buildings in Ireland and a key strategy for delivering retrofit projects may be through Energy Performance Contracting. Cork Institute of Technology (CIT) have recently completed a pilot project for the low energy retrofit of their existing $29,000 \mathrm{~m}^{2}$ teaching building constructed in 1974. The retrofit pilot project covered $1.5 \%$ of the total building floor area. The project scope consisted of design and installation of a structurally independent external envelope solution. O'Sullivan et al (O'Sullivan et al. 2013) have summarised details of the design and specification of the retrofit solution. In this paper work is summarised from experimental 


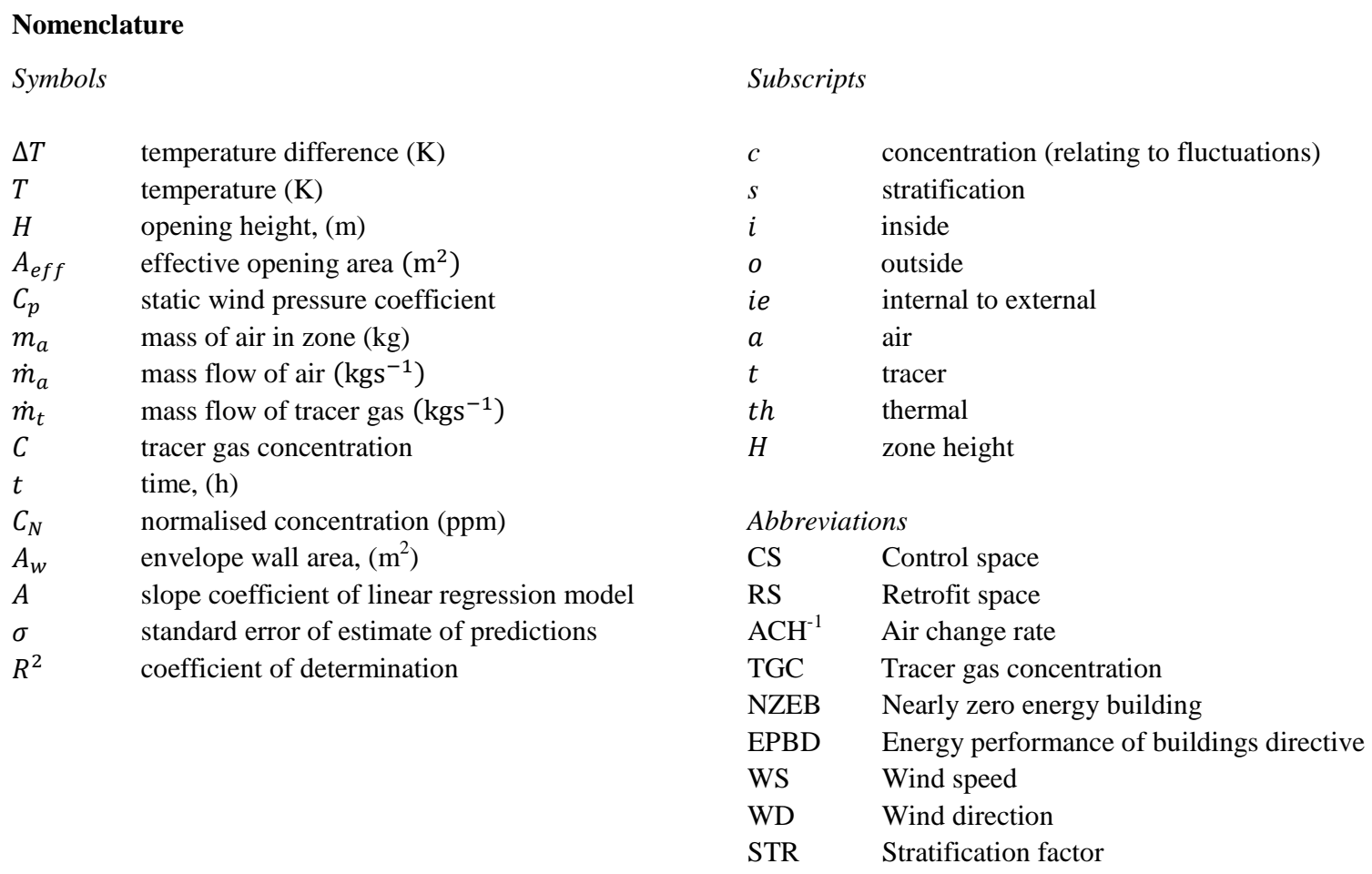

Subscripts

$\begin{array}{ll}c & \text { concentration (relating to fluctuations) } \\ s & \text { stratification } \\ i & \text { inside } \\ o & \text { outside } \\ i e & \text { internal to external } \\ a & \text { air } \\ t & \text { tracer } \\ t h & \text { thermal } \\ H & \text { zone height }\end{array}$

Abbreviations

$\begin{array}{ll}\text { CS } & \text { Control space } \\ \text { RS } & \text { Retrofit space } \\ \text { ACH }^{-1} & \text { Air change rate } \\ \text { TGC } & \text { Tracer gas concentration } \\ \text { NZEB } & \text { Nearly zero energy building } \\ \text { EPBD } & \text { Energy performance of buildings directive } \\ \text { WS } & \text { Wind speed } \\ \text { WD } & \text { Wind direction } \\ \text { STR } & \text { Stratification factor }\end{array}$

measurements of time averaged single sided ventilation rates under different ventilation opening configurations in a single sided isolated office space within the retrofit. The objective is to investigate whether modification in both the building thermophysical properties and ventilation opening design has influenced time averaged ventilation rates and the internal environment and under what conditions performance is enhanced. A control space in the existing building has been identified and utilised for comparative purposes. The spaces are shown in figure 1.

(a)

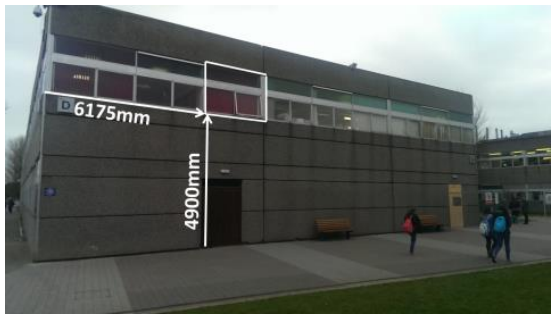

(b)

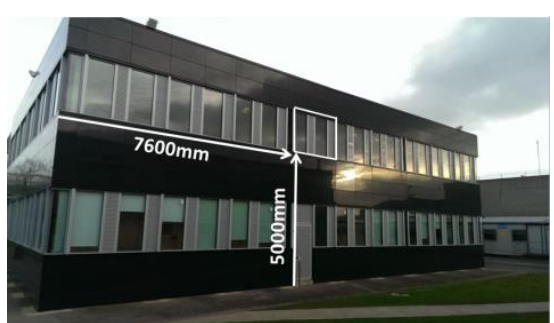

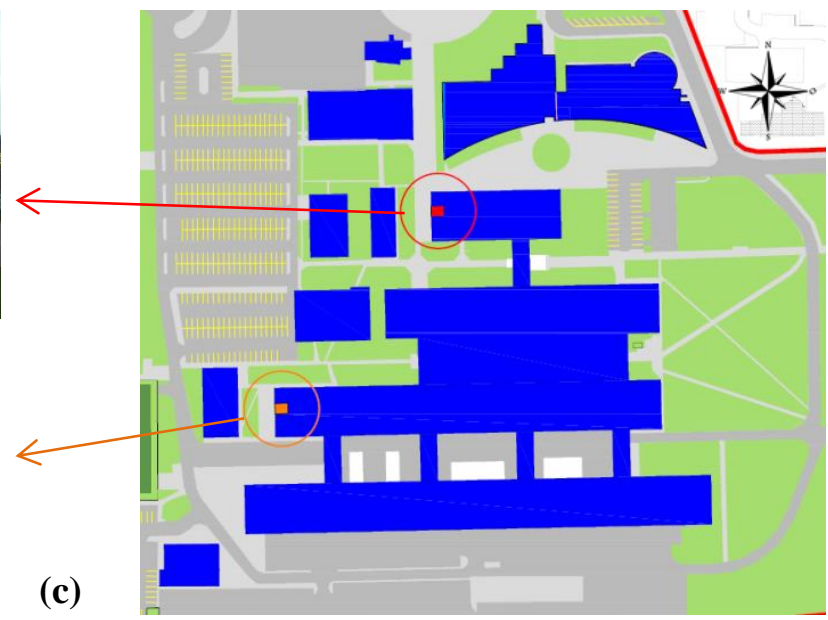

(c)

Figure 1: (a) Control space envelope location, (b) Retrofit space envelope location (c) part site plan showing location of control and retrofit spaces

Section 2 summarises location data, section 3 outlines climate information for the site. Section 4 of the paper summarises details regarding the existing building, completed retrofit strategy, natural ventilation system and operational configurations. Section 5 provides information about the ventilation rate tests including experiment setup, results and analysis. Sections 6 summarises findings from comparative studies of the internal environment in the control space and retrofit space. Results are categorised according to the four configurations detailed in section 4.2. 


\section{CONTROL AND RETROFIT SPACE LOCATION DATA}

Figure 2(a) \& (b) highlights the different obstacles in the vicinity of both the control and retrofit space sheltered locations. Static wind pressure coefficients were used as an indicator of the similarity of both locations to the conversion of free stream wind velocity and corresponding forces. $C_{p}$ Generator (http://cpgen.bouw.tno.nl), (Knoll et al, 1996), was utilised to calculate the $C_{p}$ values for each ventilation opening. Figure 3(a) \& (b) highlight the correction factors applied to base $C_{p}$ values for obstacles within a distance 5 times the obstacle height from the ventilation opening. Finally Figure 4 compares both calculated $C_{p}$ characteristics as a function of wind attack angle relative to the envelope orientation (west facing in both spaces).
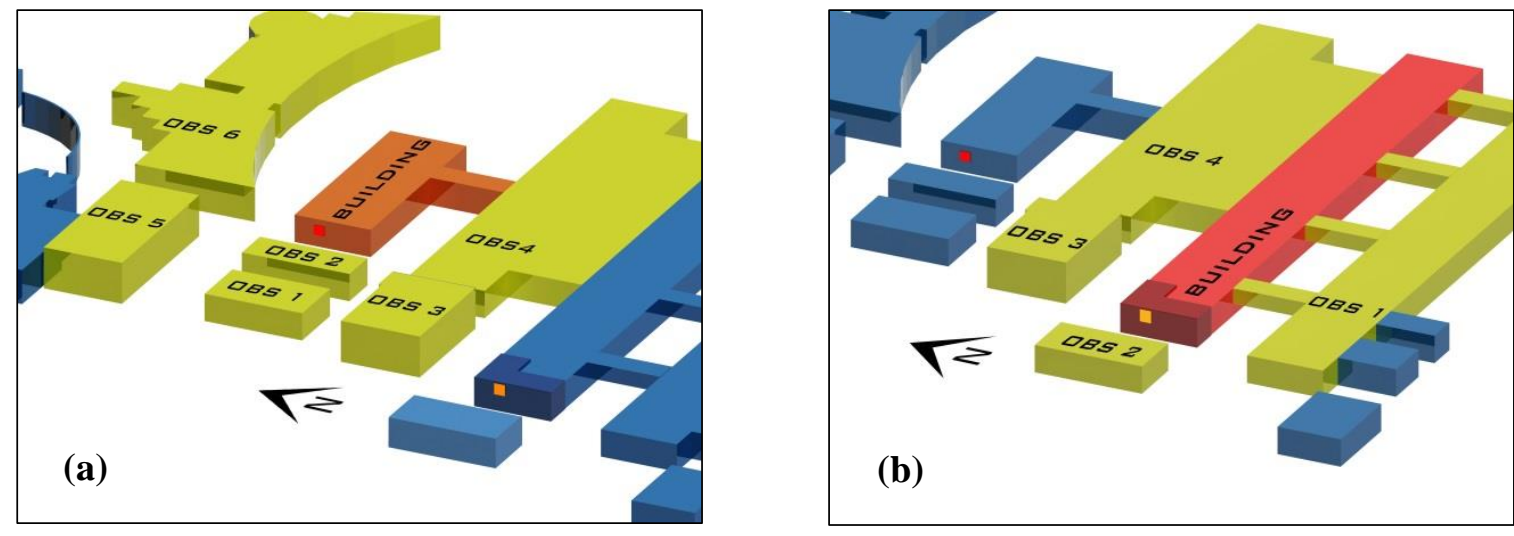

Figure 2: (a) Obstacle study control space (red square), (b) Obstacle study retrofit space (orange square)
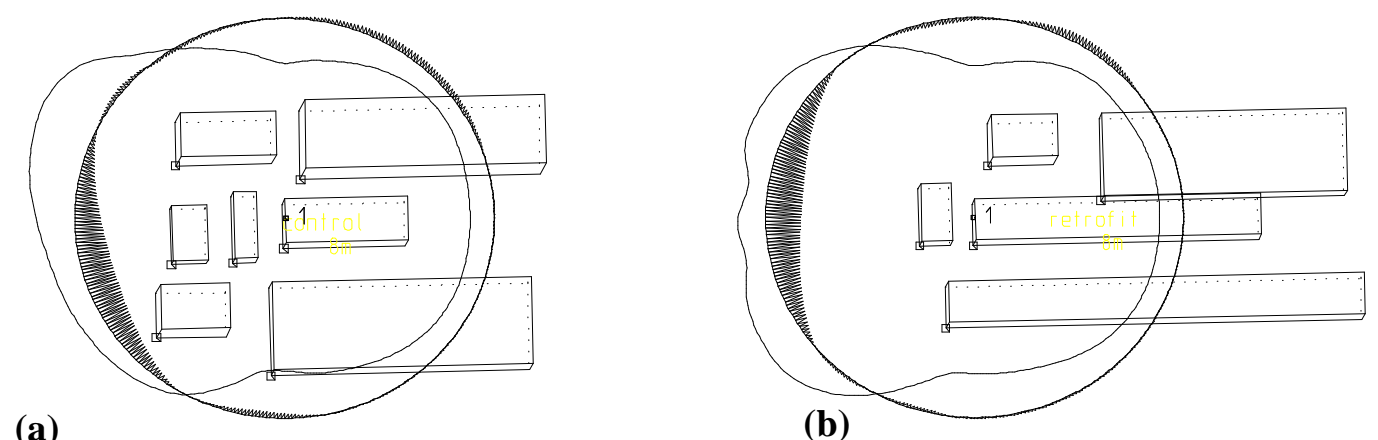

Figure 3: $C_{p}$ Generator polar plots of obstacle correction factors, (a) control space (b) retrofit space

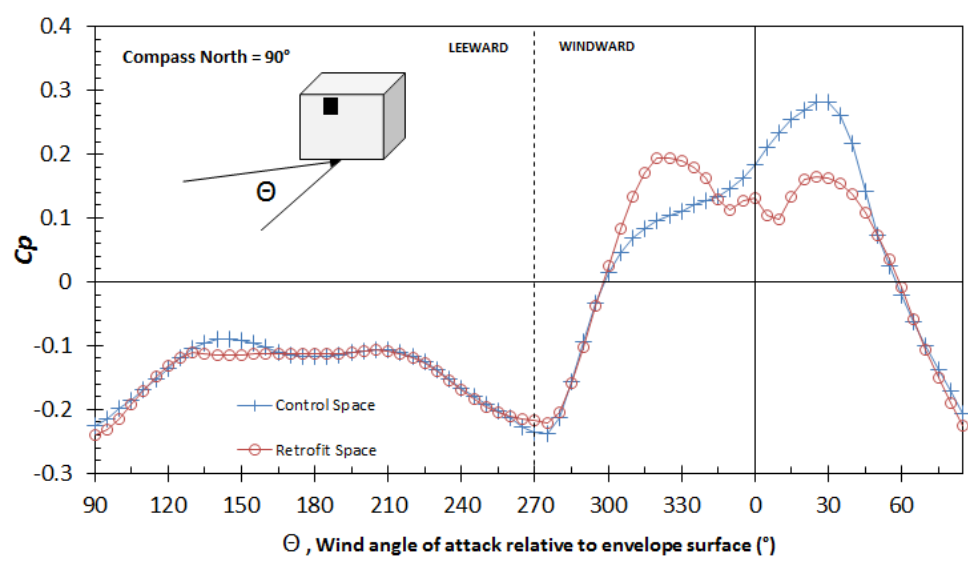

Figure $4: C_{p}$ Characteristics for control and retrofit spaces as a function of wind angle of attack 
It can be seen from Figure 4 that for leeward wind directions the $C_{p}$ values are near identical. Where the wind direction is normal to the envelope there is a difference between $C_{p}$ values of 0.053 with 0.087 between maximum values. Overall it can be said that both retrofit and control spaces exhibit comparable effects from obstacles. This suggests that while the site has sub boundary layer obstacles, the control space is still an acceptable match for the retrofit space for the purposes of investigating differences in time averaged ventilation rates under similar climate conditions.

\section{LOCAL CLIMATE (2013 \& LONG TERM)}

Ambient air temperature, solar radiation and wind speed $95^{\text {th }}$ Percentile values for May - October 2013 are presented in Table 1. Cork Airport TMY3 data also shown for comparison and was generated using Meteonorm 7 software (http://www.Meteonorm.com), (Meteonorm 7, 2012). Weather data used for the analysis in this paper was obtained from a weather station located on the roof of the retrofit space, set $6.0 \mathrm{~m}$ in from the edge of the building and at an elevation of $8.0 \mathrm{~m}$ above the finished roof level.

Table 1: 95th Percentile hourly values for Cork Airport \& local Climate at CIT

\begin{tabular}{lcccc|cccc}
\hline \multirow{3}{*}{ Month } & \multicolumn{3}{c}{ Cork Airport TMY3 95 $5^{\text {th }}$ Percentile } & \multicolumn{3}{c}{ Summer 2013 95 $5^{\text {th }}$ Percentile } \\
\cline { 2 - 8 } & $\begin{array}{c}\mathbf{G}_{\mathbf{h}} \\
\left(\mathbf{W h} / \mathbf{m}^{\mathbf{2}}\right)\end{array}$ & $\begin{array}{c}\mathbf{T}_{\mathbf{a}} \\
\left({ }^{\circ} \mathbf{C}\right)\end{array}$ & $\begin{array}{c}\mathbf{W S} \\
(\mathbf{m} / \mathbf{s})\end{array}$ & $\begin{array}{c}\mathbf{W D} \\
\left({ }^{\circ}\right)\end{array}$ & $\begin{array}{c}\mathbf{G}_{\mathbf{h}} \\
\left(\mathbf{W h} / \mathbf{m}^{\mathbf{2}}\right)\end{array}$ & $\begin{array}{c}\mathbf{T}_{\mathbf{a}} \\
\left({ }^{\circ} \mathbf{C}\right)\end{array}$ & $\begin{array}{c}\mathbf{W S} \\
(\mathbf{m} / \mathbf{s})\end{array}$ & $\begin{array}{c}\text { WD } \\
\left({ }^{\circ}\right)\end{array}$ \\
\hline May & 742 & 17.2 & 10.0 & 345 & 730 & 16.0 & 6.3 & 304 \\
June & 815 & 19.5 & 9.3 & 344 & 826 & 20.6 & 5.0 & 343 \\
July & 707 & 20.7 & 9.0 & 352 & 795 & 25.0 & 4.3 & 344 \\
August & 662 & 20.0 & 9.3 & 342 & 592 & 20.1 & 4.7 & 306 \\
September & 574 & 19.4 & 9.0 & 341 & 511 & 18.5 & 4.6 & 326 \\
October & 385 & 17.3 & 10.3 & 338 & 340 & 18.1 & 4.4 & 336 \\
\hline
\end{tabular}

\section{CONTROL SPACE \& RETROFIT SPACE ENVELOPE DETAILS}

\subsection{Envelope Components}

The external envelope retrofit solution involved the installation of a new external façade, independently supported at the base and tied into the structure at certain locations. The solution can be sub-divided into three broad modular categories; Roof module, opaque wall module and the fenestration module comprising both the glazing and ventilation openings. O'Sullivan et al (O'Sullivan et al. 2013) have already outlined in some detail the component specifications elsewhere. It should be noted that the entire existing structure has remained in place as part of the solution. Figure 5 provides information on the ventilation and fenestration component, the focus for the work presented in this paper. The main thermophysical properties for the existing building (control space) and the retrofit components are summarised in Table 2.

Table 2: Thermophysical properties of opaque external retrofit solution \& fenestration module

\begin{tabular}{llcccccc}
\hline \multicolumn{1}{c}{ Description } & $\begin{array}{c}\text { Dim. } \\
(\mathbf{m m})\end{array}$ & Location & $\begin{array}{c}\boldsymbol{\omega} / \boldsymbol{\varphi} \\
(\mathbf{W} / \mathbf{m K}) / \mathbf{h}\end{array}$ & $\begin{array}{c}\boldsymbol{f} \\
(\mathbf{W} / \mathbf{m K})\end{array}$ & $\begin{array}{c}\mathbf{U}_{\text {wall }} \\
\left(\mathbf{W} / \mathbf{m}^{2} \mathbf{K}\right)\end{array}$ & $\begin{array}{c}\mathbf{U}_{\text {fenestr. }} \\
\left(\mathbf{W} / \mathbf{m}^{2} \mathbf{K}\right)\end{array}$ \\
\hline 1 & Existing Internal Block & 100 & & & & & \\
2 & BASF Wall-tite Spray Foam & 86 & Control & $5.49 / 1.017$ & 0.608 & 3.633 & 6.0 \\
3 & Existing aggregate panel & 125 & Space & & & & \\
4 & Air gap & 30 & & & & & \\
5 & Kingspan ceramic granite panel & 12 & & & & \\
6 & Kingspan support rail & 37 & Retrofit & $5.92 / 0.963$ & 0.004 & 0.090 & 0.84 \\
7 & Kingspan KS 1100 insulated panel & 125 & Space & & & \\
8 & AMS support mullion & 125 & & & & & \\
\hline
\end{tabular}



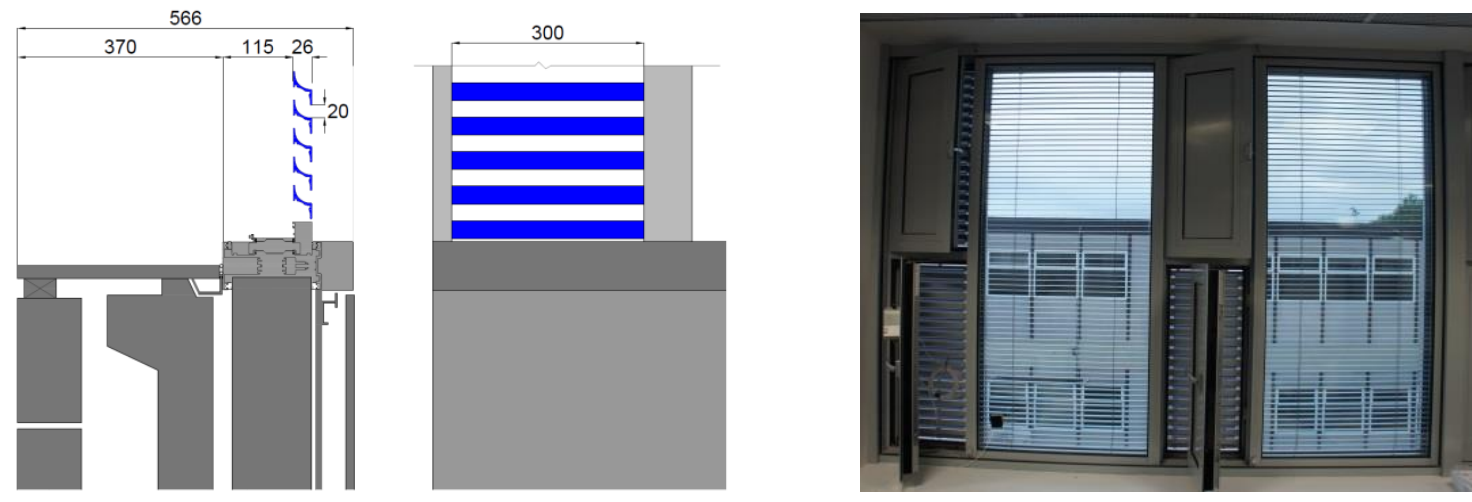

Figure 5: (a) Ventilation Opening detail elevation \& section, (b) Internal view of installed fenestration module

\subsection{Ventilation System}

For most enclosed spaces in the existing building the ventilation system is based on single sided top hung pivoting window sections. There is generally one opening window per structural grid. These are the original 1974 windows. In the retrofit space fenestration system, the ventilation module uses a flush faced external louvre with individual air inlet sections (see figure 5). Inside this louvre ventilation is supplied using dedicated insulated doors controlled either manually or automated based on conditions in the enclosed spaces (see Table 3 for different operating configurations and effective opening areas). The overall thermal transmittance performance of this unit including doors and linear transmittance is $0.84 \mathrm{~W} / \mathrm{m}^{2} \mathrm{k}$, according to IS EN 10077-2:2012 (NSAI 2012). The new fenestration module resulted in an overall opaque/transparent area ratio reduction of 20\%. Unwanted ventilation through adventitious openings has also been greatly reduced. The retrofit envelope air permeability was tested in accordance with BS EN 13829:2001 (NSAI 2001). The envelope achieved an air permeability of $1.76\left(\mathrm{~m}^{3} / \mathrm{hr}\right) / \mathrm{m}^{2}$ at $50 \mathrm{~Pa}$ building pressure. The existing structure was measured as $14.77\left(\mathrm{~m}^{3} / \mathrm{hr}\right) / \mathrm{m}^{2}$.

\section{TIME AVERAGED VENTILATION RATE $\left(\mathrm{ACH}^{-1}\right)$ MEASUREMENTS}

\subsection{Tracer Gas Concentration (TGC) Decay technique}

The ventilation rate for the control space and retrofit space was measured using a single zone TGC decay technique. TGC decay techniques are among the most efficient to assess airflow patterns within buildings. They consist of 'marking' the air with a tracer gas (Roulet 2007). Carbon Dioxide $\left(\mathrm{CO}_{2}\right)$ was chosen as the tracer gas for this work due to the ease of use, availability of analysis equipment, its density being similar to air and cost. $\mathrm{CO}_{2}$ qualities as a tracer are summarised in Table 7.2 of Roulet (Roulet 2007). One main concern when using $\mathrm{CO}_{2}$ as a tracer gas can be the presence of a large background concentration and, if constant, account must be taken for this in analysis of data by substituting the difference between indoor and outdoor concentration for indoor concentration in the analysis (Persily 1997). For each of the tests presented in this work outdoor $\mathrm{CO}_{2}$ concentrations during the test and indoor zone $\mathrm{CO}_{2}$ concentrations prior to the test start were monitored and test start time concentration levels adjusted accordingly. Overall average outdoor $\mathrm{CO}_{2}$ concentration during testing (as a percentage of the indoor concentration for each configuration) are summarised in Table 4. For the TGC decay technique a suitable quantity of tracer gas is injected prior to the test to achieve a measureable initial concentration, $C_{i o}(0)$. After the initial pulse period, the injection is stopped and $\dot{m}_{t}(0)=0$. Once the pulse injection has stopped the tracer gas is then mixed within the zone until the average uniformity concentration difference for the test reaches an acceptable level. 
Table 3: Summary of ventilation opening data \& operating configurations

Configuration

$C S=$ Control Space; $R S=$ Retrofit Space; $M=$ Manual; $A=$ Automated with manual override (flow schematics not to scale)

The tracer gas is then monitored using a gas analyser from the test start time until the test end time, in this instance once the concentration has returned at or close to the pre-test concentration levels. The differential equation describing the tracer gas mass balance can be written based as (Roulet 2007):

$$
m_{a(i)} \frac{d C_{i z}}{d t}=\dot{m}_{t}+\dot{m}_{a(o i)}\left(C_{o i}-C_{i o}\right)
$$

Rearranging, taking the integral of both sides and then dividing by $\Delta \mathrm{t}$ we can derive an equation that describes the $A C H^{-1}$ based on tracer gas concentration:

$$
\frac{\dot{m}_{\text {air }(o i)}}{m_{\text {air }(i)}}=\frac{\dot{m}_{t}}{\left(C_{o i}-C_{i o}\right)}-\frac{1}{\Delta t}[\ln \Delta C(0)-\ln \Delta C(t)]
$$

Where the decay rate of TGC displays a smooth profile the ventilation rate can be assumed to be constant over the measurement period. A non-smooth or fluctuating concentration rate indicates a non-steady ventilation rate, the extent based on the magnitude and frequency of fluctuation. There are a number of decay techniques that can be used to obtain an average ventilation rate (ASTM 2011; Sherman 1990). 
Figure 7 presents results of each test using a normalised TGC value, $C_{N}$, to allow easier comparison of test "decay rate smoothness" and unsteadiness magnitude across the range of test conditions. $C_{N}$ can be defined as:

$$
C_{N}=\ln \frac{C(t)-C_{0}}{C(0)-C_{0}}
$$

According to Sherman (Sherman 1990) using a regression technique will result in the best single estimate of ventilation to match the data, though where the ventilation rate isn't constant the result will be a biased estimate of the average air change rate. $A C H^{-1}$ for each has been calculated using $C_{N}$ and the decay regression method in ASTM E-741(ASTM 2011):

$$
\ln C_{N}=-A t+\ln C_{N}(0)
$$

Refer to the tables in Figure 7 for $R^{2}$ values for each test as well as $\sigma_{c}$, an indicator of how unsteady concentration decay was during tests. $\sigma_{c}$ is the standard error of estimate in prediction of $Y_{i}, Y_{i}^{\prime}$, from the regression model and is used as a measure of the magnitude of concentration fluctuation during decay for each test and is defined as:

$$
\sigma_{c}=\sqrt{\frac{\sum_{i=1}^{N}\left(Y_{i}-Y_{i}^{\prime}\right)^{2}}{N-1}}
$$

\subsection{Experiment setup and Test conditions}

38 TGC Decay tests were completed in total. Table 4 gives a summary of conditions for tests completed under each operational configuration. Tests were completed in accordance with the procedures set out in ASTM E741-11. Two tracer gas sampling locations and a single gas injection location were used within the zone being tested. This was a standard $\mathrm{CO}_{2}$ cylinder and heated flow regulator. $\mathrm{CO}_{2}$ concentration analysers were AlphaSense IRC-A1 Non Dispersive Infra-Red (NDIR) Sensors. $\mathrm{CO}_{2}$ sampling frequency was $1 \mathrm{~Hz}$. As $\mathrm{CO}_{2}$ is denser than air $(\sigma=1.53)$ the gas was actively mixed as it entered the space. A maximum $10 \%$ acceptable uniformity of concentration criteria between both sampling locations in accordance with ASTM E741-11 was used to determine when there had been sufficient mixing. Refer to Figure 6 for equipment layout for both the control space and retrofit space. 
Table 4: Schedule of experimental tests and conditions

\begin{tabular}{lcccccc}
\hline \multicolumn{1}{c}{ Config. } & $\begin{array}{c}\text { No of } \\
\text { tests }\end{array}$ & $\begin{array}{c}\text { Range of test } \\
\text { durations }\end{array}$ & $\begin{array}{c}\text { Average } \\
\text { Conc. } \\
\text { uniformity }\end{array}$ & $\begin{array}{c}\text { (Ave) Start } \\
\text { PPM Range } \\
\text { (Adjusted.) }\end{array}$ & $\begin{array}{c}\text { (Ave) End } \\
\text { PPM Range } \\
\text { (Adjusted.) }\end{array}$ & $\begin{array}{c}\text { Average } \\
\text { B.G. PPM } \\
\text { (\%) }\end{array}$ \\
\hline CS-1.0/M & 13 & $24-90 \mathrm{~min}$ & $2.57 \%$ & $3181-6203$ & $175-1214$ & 10.3 \\
RS-2.0/M & 6 & $26-60 \mathrm{~min}$ & $1.51 \%$ & $3538-5431$ & $364-1481$ & 12.3 \\
RS-3.0/A & 6 & $31-60 \mathrm{~min}$ & $4.46 \%$ & $3511-5051$ & $703-1327$ & 13.4 \\
RS-4.0/A/M & 13 & $30-161 \mathrm{~min}$ & $2.37 \%$ & $3647-4746$ & $212-1067$ & 13.0 \\
\hline
\end{tabular}
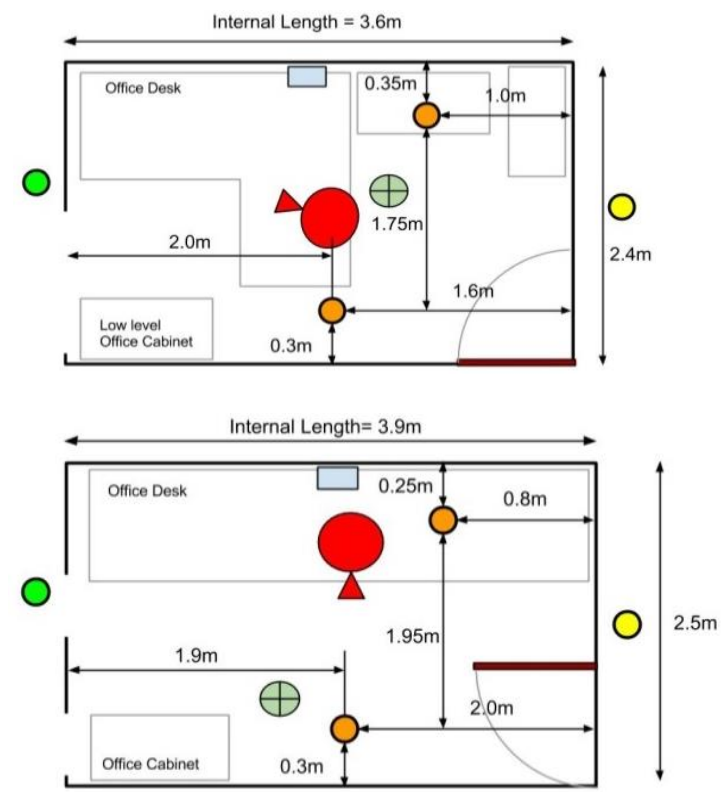

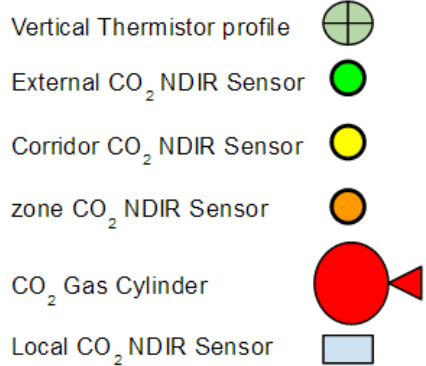

Local $\mathrm{CO}_{2} \mathrm{NDIR}$ Sensor

Figure 6: TCG Decay test equipment location drawing (NTS) (a) control space (b) retrofit space

\subsection{Results \& Analysis}

The time period of each test varied based on the configuration and according to the guidelines in table 2 of ASTM E-741-11 (ASTM, 2011). Figure 7 presents results from all TGC decay tests under different operating configurations. Data is presented using $\ln C_{N}$ for each test. $\mathrm{ACH}^{-1}$ have been calculated using the decay regression technique outlined in section 5.1. Magnitudes are estimated based on the slope coefficient resulting from the best linear fit equation. Table 5 contains summary data regarding the 38 tests and individual values are also tabulated in Figure 7 alongside graphed results. The control space has consistently higher time averaged ventilation rates with an average value of $4.2 \mathrm{~h}^{-1}$ and standard deviation of $1.52 \mathrm{~h}^{-1}$. In the retrofit space RS-4.0 had the best performance profile with average value of $3.8 \mathrm{~h}^{-1}$ and standard deviation of $1.0 \mathrm{~h}^{-1}$ indicating a slightly more concentrated spread of results. Based on the guideline values for indoor air quality classification in BS EN 13779:2007 (NSAI 2007) both the control space and retrofit space time averaged ventilation rates can be classified as IDA1 (High). ACH values were on average lower for the RS-2.0 \& RS-3.0 configurations although there were individual instances of high $\mathrm{ACH}$ values above $5.0 \mathrm{~h}^{-1}$. Where there is steady ventilation rate conditions during tests the lines representing the concentration decay should display a smooth linear profile. The magnitude of the deviations, $\sigma_{c}$ about the resulting best fit linear regression equation can be used as an indicator of the potential unsteadiness in ventilation rates.

Regarding the type of ventilation flow conditions in control and retrofit spaces there were consistently higher $\sigma_{c}$ values and visibly more unstable decay profiles in the control space. This would suggest there were higher unsteady flow effects during testing in the control space. The retrofit space configuration RS-4.0 also displayed some tests with unsteady flow effects likely present with the same maximum $\sigma_{c}$ values although the average RS-4.0 $\sigma_{c}$ was $35 \%$ lower. The profiles of the decay are consistently more stable for RS-2.0 \& RS-3.0 with average $\sigma_{c}$ values $57.5 \%$ and $76.5 \%$ lower respectively. 


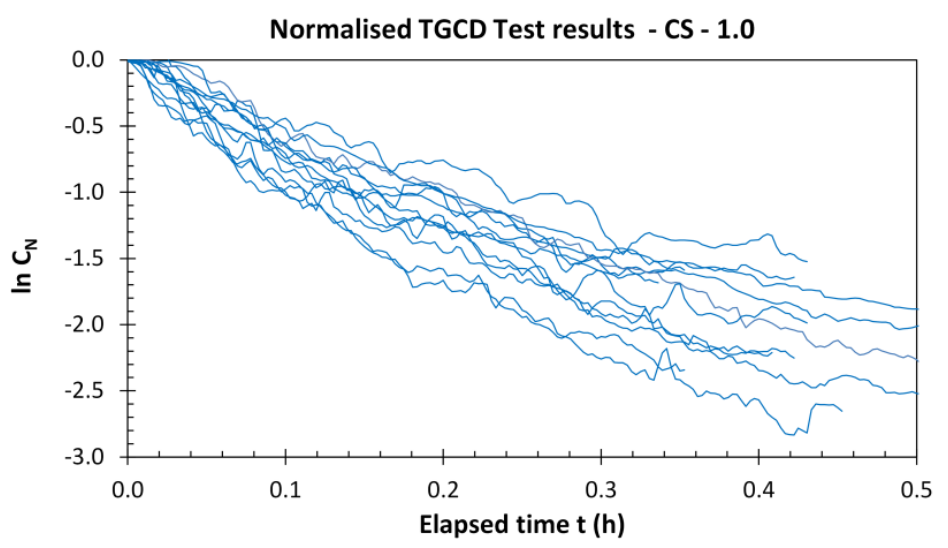

\begin{tabular}{cccc}
\multicolumn{4}{c}{ TGCD Test Data - CS-1.0 } \\
\hline Test No. & ACH & $\boldsymbol{\sigma}_{\mathbf{c}}$ & $\mathbf{R}^{\mathbf{2}}$ \\
\hline 1 & 6.0 & 0.098 & 0.959 \\
2 & 5.3 & 0.104 & 0.955 \\
21 & 1.9 & 0.038 & 0.852 \\
22 & 3.9 & 0.077 & 0.943 \\
26 & 3.4 & 0.048 & 0.942 \\
3 & 5.9 & 0.050 & 0.990 \\
4 & 5.0 & 0.080 & 0.963 \\
14 & 4.1 & 0.093 & 0.927 \\
27 & 4.5 & 0.122 & 0.916 \\
33 & 3.6 & 0.061 & 0.958 \\
34 & 2.0 & 0.050 & 0.781 \\
35 & 6.4 & 0.103 & 0.968 \\
36 & 2.7 & 0.042 & 0.928 \\
\hline
\end{tabular}

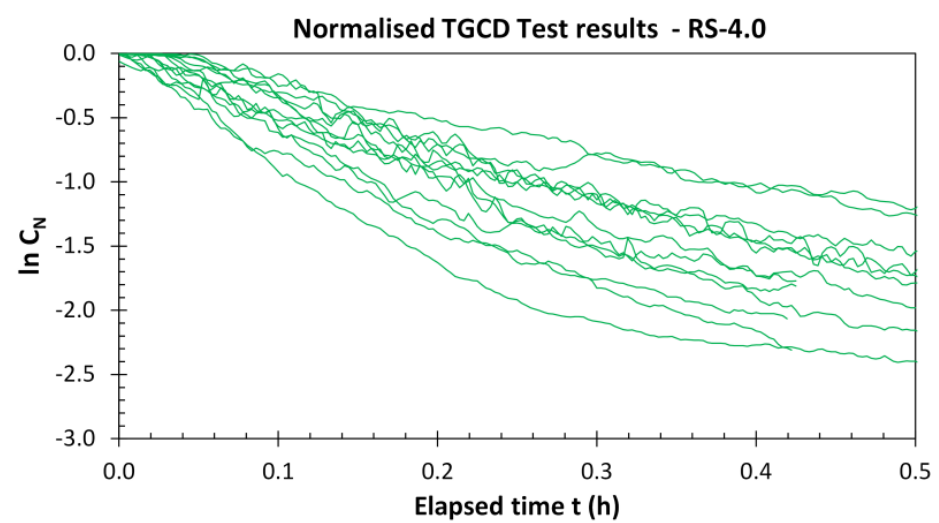

\begin{tabular}{cccc}
\multicolumn{4}{c}{ TGCD Test Data - RS-4.0 } \\
\hline Test No. & ACH & $\mathbf{\sigma}_{\mathbf{c}}$ & $\mathbf{R}^{\mathbf{2}}$ \\
\hline 8 & 5.8 & 0.063 & 0.982 \\
10 & 4.3 & 0.034 & 0.987 \\
11 & 4.8 & 0.077 & 0.962 \\
12 & 4.2 & 0.120 & 0.858 \\
13 & 4.2 & 0.045 & 0.980 \\
17 & 4.5 & 0.056 & 0.977 \\
18 & 3.2 & 0.047 & 0.960 \\
19 & 2.6 & 0.011 & 0.996 \\
20 & 2.5 & 0.023 & 0.975 \\
24 & 3.3 & 0.030 & 0.980 \\
28 & 4.5 & 0.077 & 0.958 \\
30 & 3.1 & 0.030 & 0.973 \\
32 & 2.3 & 0.019 & 0.980 \\
\hline
\end{tabular}

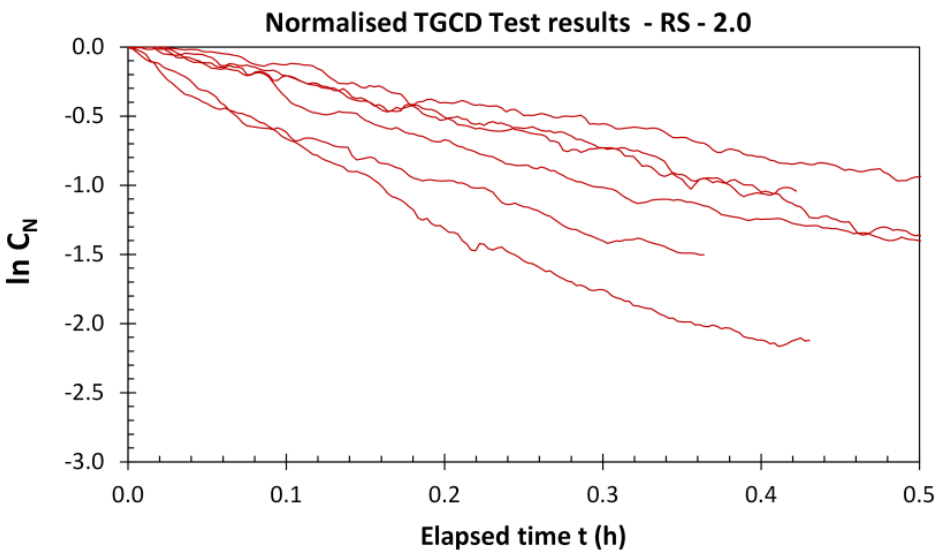

TGCD Test Data - RS-2.0

\begin{tabular}{cccc}
\hline Test No. & $\mathbf{A C H}$ & $\boldsymbol{\sigma}_{\mathbf{c}}$ & $\mathbf{R}^{\mathbf{2}}$ \\
\hline 5 & 5.1 & 0.058 & 0.981 \\
6 & 4.0 & 0.051 & 0.979 \\
15 & 2.6 & 0.032 & 0.967 \\
23 & 2.8 & 0.010 & 0.996 \\
29 & 2.6 & 0.017 & 0.994 \\
31 & 1.5 & 0.021 & 0.948 \\
\hline
\end{tabular}

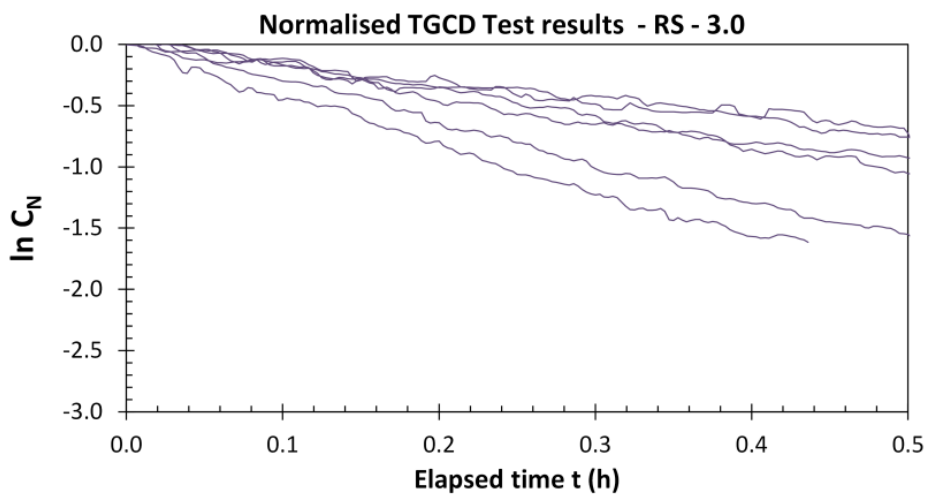

TGCD Test Data - RS-3.0

\begin{tabular}{|c|c|c|c|}
\hline Test No. & $\mathrm{ACH}$ & $\sigma_{c}$ & $\mathrm{R}^{2}$ \\
\hline 7 & 3.8 & 0.024 & 0.994 \\
\hline 16 & 1.9 & 0.021 & 0.975 \\
\hline 25 & 2.2 & 0.007 & 0.997 \\
\hline 37 & 2.9 & 0.015 & 0.992 \\
\hline 38 & 1.4 & 0.029 & 0.942 \\
\hline 39 & 1.5 & 0.009 & 0.991 \\
\hline
\end{tabular}

Figure 7: - Natural logarithm of $C_{N}$ as a function of elapsed time for each test \& tabulated data of associated results for $\mathrm{ACH}^{-1} \sigma_{c} \& R^{2}$ 
Table 5: ACH ${ }^{1}$ Controlled Test Results Overview

\begin{tabular}{lcccccccccc}
\hline $\begin{array}{l}\text { Test } \\
\text { Config. }\end{array}$ & $\begin{array}{c}\text { Max } \\
\boldsymbol{A} \boldsymbol{C H}^{\boldsymbol{1}}\end{array}$ & $\begin{array}{c}\text { Min } \\
\boldsymbol{A} \boldsymbol{C H}^{\boldsymbol{1}}\end{array}$ & $\begin{array}{c}\text { Std. } \\
\text { Dev. }\end{array}$ & $\begin{array}{c}\boldsymbol{A} \boldsymbol{A v e} \\
\boldsymbol{A} \boldsymbol{H}^{\boldsymbol{1}}\end{array}$ & $\begin{array}{c}\text { Max } \\
\boldsymbol{\sigma}_{\boldsymbol{c}}\end{array}$ & $\begin{array}{c}\text { Min } \\
\boldsymbol{\sigma}_{\boldsymbol{c}}\end{array}$ & $\begin{array}{c}\text { Ave } \\
\boldsymbol{\sigma}_{\boldsymbol{c}}\end{array}$ & $\begin{array}{c}\text { WS } \\
\text { Range } \\
(\mathbf{m} / \mathbf{s})\end{array}$ & $\begin{array}{c}\text { No. of } \\
\mathbf{W} / \mathbf{L} \\
\text { tests }\end{array}$ & $\begin{array}{c}\Delta \mathbf{T}_{\text {ie }} \\
\text { Range }\end{array}$ \\
\hline CS-1.0 & 6.4 & 1.9 & 1.5 & 4.2 & 0.1219 & 0.0381 & 0.0744 & $1.4-5.2$ & $9 / 4$ & $4.2-8.9$ \\
$\mathrm{RS}-4.0$ & 5.8 & 2.3 & 1.0 & 3.8 & 0.1201 & 0.0114 & 0.0487 & $1.4-5.2$ & $7 / 6$ & $0.5-5.5$ \\
$\mathrm{RS}-2.0$ & 5.1 & 1.5 & 1.3 & 3.1 & 0.0577 & 0.0101 & 0.0316 & $3.3-4.2$ & $4 / 2$ & $1.1-5.3$ \\
RS-3.0 & 3.8 & 1.4 & 0.9 & 2.3 & 0.0286 & 0.0073 & 0.0175 & $1.5-4.5$ & $4 / 2$ & $0.4-7.1$ \\
\hline
\end{tabular}

Having measured time averaged ventilation rates using the TGC decay regression technique the next step of the analysis will be to investigate whether the dominant driving forces were different for each operating configuration. The two main forces that can give rise to ventilation rates are stack effect, generated by temperature difference across the building envelope in single sided ventilation flow models, and pressure at the building surface due to wind effect (magnitude and direction). Single sided ventilation rates due to these combined forces can be estimated using a number of different semi-empirical models with correction factors applied to take account of unsteady flow effects. Warren (Warren, 1978) proposed 2 separate correlations for stack and wind effect, taking the larger of the two to quantify ventilation rate. Dascalaki (Dascalaki et al, 1996) proposed an alternative correlation to take account of wind effects. More recently Larsen et al (Larsen \& Heiselberg 2008) proposed a more complex correlation that takes account of the thermal effects, wind speed \& direction. Larsen et al also found that the dominating force differs between wind speed and $\Delta T_{i e}$ depending on the ratio between these forces and the wind direction. These correlations have been recently compared with experimental results (Caciolo et al 2011 and 2013) concluding that in the case of windward opening the best results were obtained with the Warrens' correlation. Warrens' correlation also captured both positive (increased mixing layer) and negative (opening effective temperature difference decrease) effects due to wind quite well for windward conditions. In the case of leeward openings all correlations overestimated the air change rate. This work was based on plain opening and top/bottom pivoting opening window types. Experimental results presented in this paper are also suitable for such analysis which will be presented in a future paper. Figure 8 shows a plot of wind direction and magnitude for all experimental sets presented here and are separated by configuration.

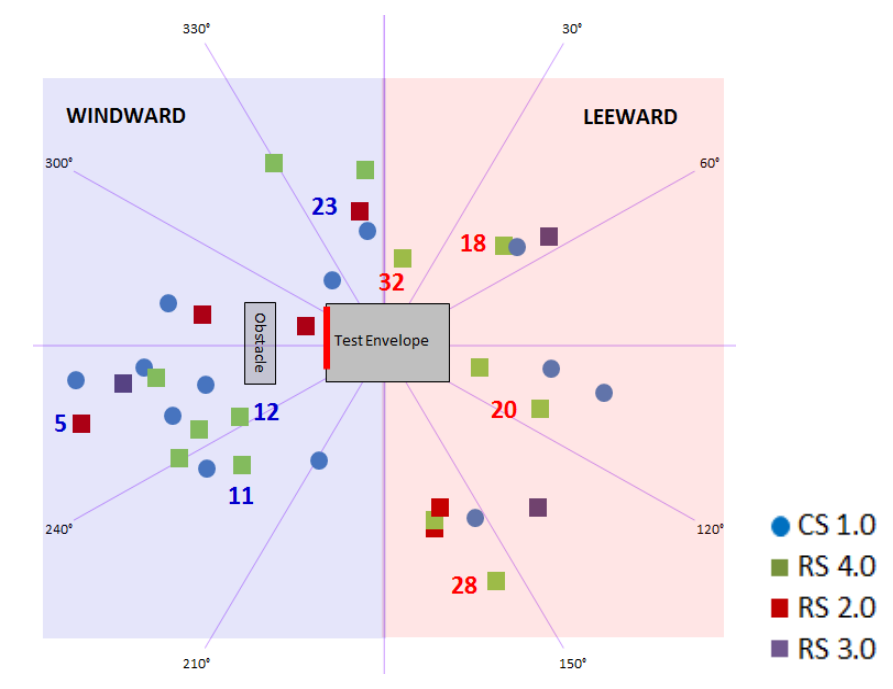

Figure 8: Wind data for ventilation rate tests for each configuration.

\section{INTERNAL ENVIRONMENT}

\subsection{Zonal Vertical Temperature Distribution}

Acceptable thermal comfort ranges for building occupants are defined in the various standards (NSAI 2007; NSAI 2006). Adjustment of recommended zone air temperature thresholds is possible depending on different combinations of air speed, turbulence intensity, mean surface radiant temperature and air temperature (ASHRAE 2009). However occupants can still experience local thermal discomfort even when their body is in thermal neutrality as a whole. Local thermal discomfort 
is generally triggered by phenomena such as draughts, radiation asymmetry \& vertical temperature difference and the nature of these can be correlated with space structural thermophysical properties and ventilation system characteristics. Recommendations for acceptable conditions to restrict percentage dissatisfied based on local thermal discomfort phenomena are outlined in ISO7730. While radiation asymmetry has likely been modified as a result of the retrofit works and can lead to high percentages of people expressing discomfort, particularly for warm ceilings and cool walls, and in some cases have a greater contribution to thermal discomfort than vertical temperature difference, the objectives of this work was not to quantify explicitly this phenomena. The presence of draughts is not investigated here although feedback from occupants suggests a lack of perceived air movement is a concern and may be the subject of future investigations. Vertical temperature difference is the focus for this work. According to ISO 7730 personal dissatisfaction increases exponentially as the vertical temperature difference increases (NSAI 2006). A Category A thermal environment should have a vertical air temperature difference less than $3^{\circ} \mathrm{C}$ and less than $2^{\circ} \mathrm{C}$ between ankles and head. As well as local thermal discomfort thermal stratification has practical importance for quantifying the level of zonal temperature gradient, effecting envelope flows where there are defined low and high level ventilation openings. However it can also be viewed as a source of uncertainty when modelling zone ventilation and air temperatures using multi-zone airflow modelling techniques. Investigating the extent of variation in the relative strength of zone stratification as a result of a deep envelope is important in understanding how thermal comfort and ventilation rates have been affected. There are generally three possible "good" profiles for vertical air temperature profiles; linear, a two layer profile $\&$ a mixed profile ( $\mathrm{Li}$ 2002). The experimental investigation allows a better understanding of whether these profiles are applicable in both control and retrofit spaces. In un-insulated or poorly insulated buildings stratification may also affect heat transfer with walls and ceiling/roof slabs, modifying level of coupling between ventilation and thermal mass. In order to investigate what level of thermal stratification was present in the existing building and how this has been modified by the retrofit strategy the vertical temperature profile was measured at 8 vertical locations during each of the $A C H^{-1}$ tests and also for an extended period covering $9^{\text {th }}$ June 2013 to $23^{\text {rd }}$ July 2013. The use of an empirically derived dimensionless Stratification Factor (STR) to characterise the relative strength of zone vertical temperature distribution compared to zone envelope temperature difference shall be used for analysis purposes (Etheridge 2011):

$$
\frac{\Delta T_{s}}{\Delta T_{i e}}=\frac{T_{H}-T_{0}}{T_{H / 2}-T_{E}}
$$

This STR is used in the presentation and analysis of results as it is a good indicator of whether or not the vertical temperature distribution is having an appreciable effect on ventilation performance and also whether or not it is constituting to sub zone airflow phenomena that might be important when assessing cooling potential of the ventilation system in cooling mode.

\subsubsection{Instrument setup}

Hanwell Radio-logger RL4000 wireless data loggers and precision thermistors with an accuracy of +/$0.1^{\circ} \mathrm{C}$ between $-25^{\circ} \mathrm{C}$ to $50^{\circ} \mathrm{C}$ were used for vertical temperature distributions. Measurements were recorded every 10 minutes in the retrofit space and every 5 minutes in the control space. Measurements were taken at 8 vertical positions from floor to underside of the false ceiling level spaced evenly throughout the $3.2 \mathrm{~m}$ height. Surface and air temperatures are continuously logged using Gemini Tiny-tag data loggers.

\subsubsection{Results \& Analysis}

Comparison of a number of vertical temperature distribution profiles, measured at the end of different $\mathrm{ACH}^{-1}$ test periods, are presented for tests recording high ventilation rates (figure 9(a)), and for high STR values, (figure 9(b)). All data was obtained during a particularly warm period with external temperatures reaching 10 year highs. Table 6 summarises STR and $\sigma_{c}$ for a number of selected tests highlighting the spread of STR values across the different configurations. Figure 10(a) and 10(b) present the frequency and cumulative distributions for $S T R$ values for both occupied and unoccupied hours for the control and retrofit spaces for the period $9^{\text {th }}$ June 2013 to $23^{\text {rd }}$ July 2013. 
CS-1.0
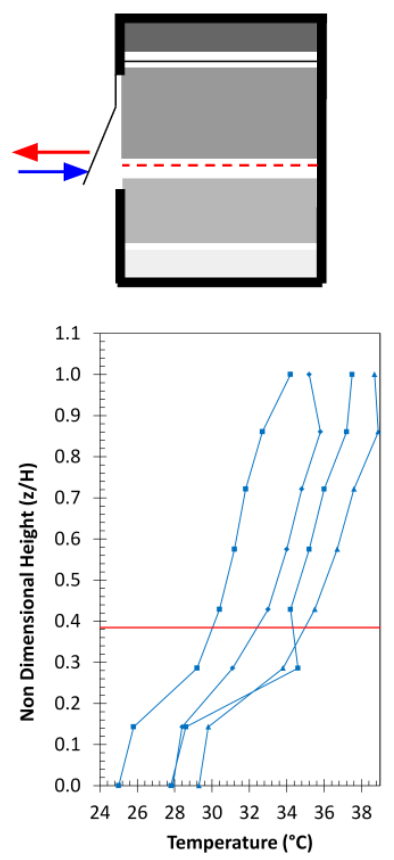

RS-4.0
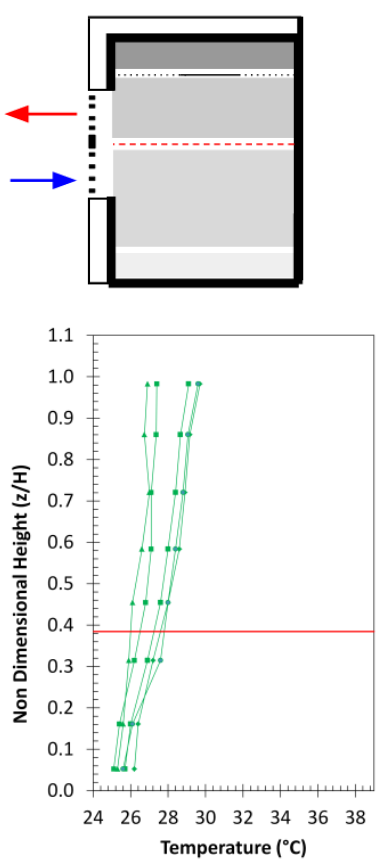

RS-2.0
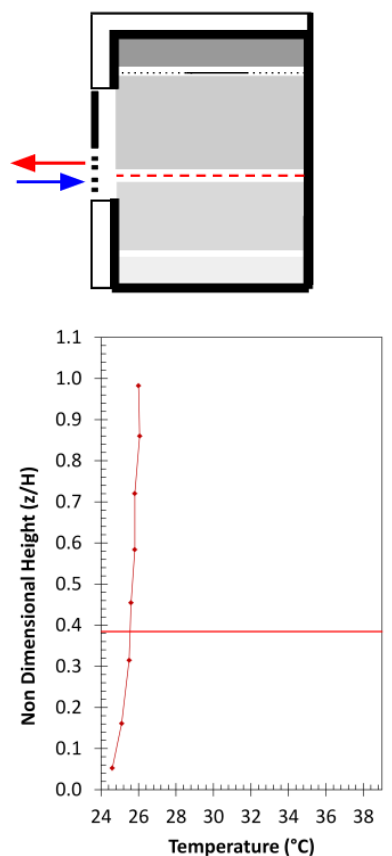

RS-3.0
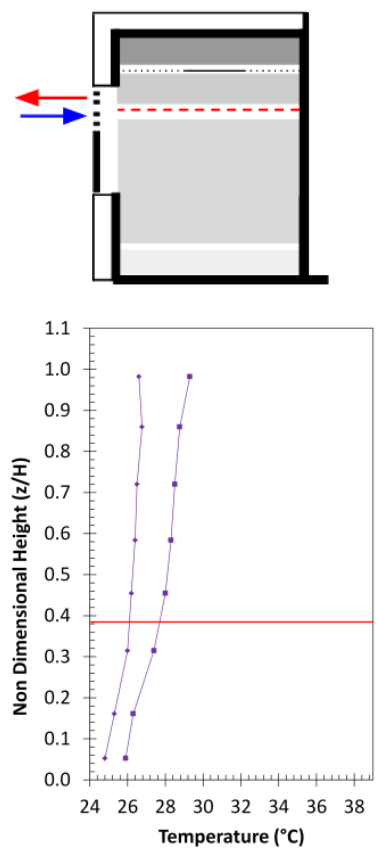

(a) Vertical Temperature Profiles for tests with STR > 1.0 for each configuration
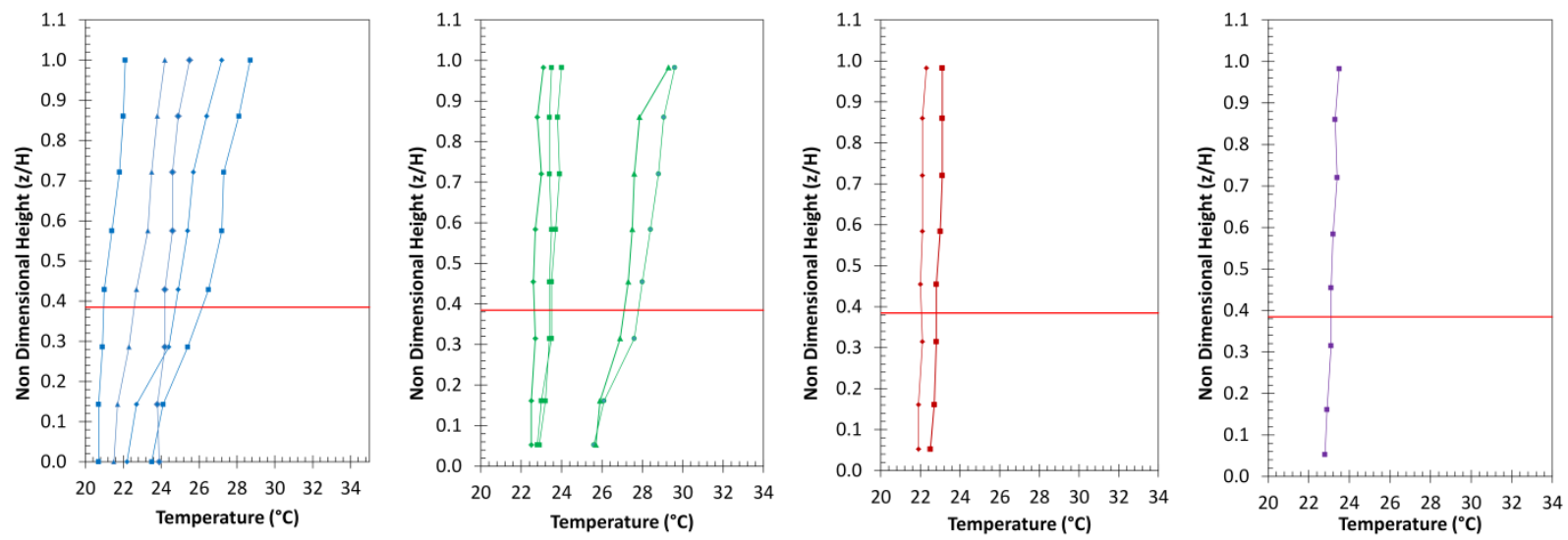

(b) Vertical Temperature Profiles for tests with high $\mathbf{A C H}^{-1}$ for each configuration (generally $\geq 4.0 \mathrm{ACH}^{-1}$ )

Figure 9: Results from zone vertical temperature distribution measurements during $\mathrm{ACH}^{-1}$ testing for retrofit and control configurations.

With STR values > 1.0 there is some variation in vertical temperature distribution for 5 of the tests under configuration RS-4.0 though the control space, CS-1.0, generally exhibits higher stratification than all configurations in the retrofit space. RS-4.0, full ventilation opening height, demonstrates that some stratification potential exists in the low energy retrofit space under certain conditions. Vertical temperature distribution under free cooling from outdoor air has been substantially modified following the retrofit works. Configuration RS-4.0 still displays some vertical temperature difference however, RS-2.0 \& RS-3.0 have little or no vertical temperature variations except for 1 or 2 tests when STR > 1.0.

Table 6: STR values for selected tests

\begin{tabular}{cccc}
\hline Location/Config & Test & STR & $\boldsymbol{\sigma}_{\boldsymbol{c}}$ \\
\hline CS-1.0 & 2 & 0.062 & 0.104 \\
RS-3.0 & 37 & 0.090 & 0.015 \\
RS-4.0 & 8 & 0.110 & 0.063 \\
RS-3.0 & 38 & 0.280 & 0.029 \\
CS- 1.0 & 22 & 0.470 & 0.077 \\
CS- 1.0 & 14 & 1.050 & 0.093 \\
\hline
\end{tabular}




\begin{tabular}{cccc}
\hline CS-1.0 & 33 & 1.050 & 0.061 \\
RS-4.0 & 17 & 1.330 & 0.056 \\
RS-4.0 & 24 & 1.810 & 0.030 \\
\hline
\end{tabular}

Figure 10 shows how stratification is substantially reduced during overnight periods. The $95^{\text {th }}$ percentile value for unoccupied hours of 0.611 is largely based on conditions up to around 21:00 each evening where there is still significant stratification. Both spaces monitored are west facing and this suggests an association with incident solar irradiation and the occurrence of peak conditions later in the evenings. Most of the peak conditions take place at this time even though peak day time air temperatures occur as early as 11:45am. The retrofit occupied hours $95^{\text {th }}$ percentile value of 2.59 does highlight that there is stratification still present in the space and it has a significant relative strength compared to $\Delta T_{i e}$. Temperatures at the surface of the exposed roof slab are often $2-3^{\circ} \mathrm{C}$ higher than would be reported based on a mid-level zone thermostat which can be significant in ventilate cooling of a low energy space.
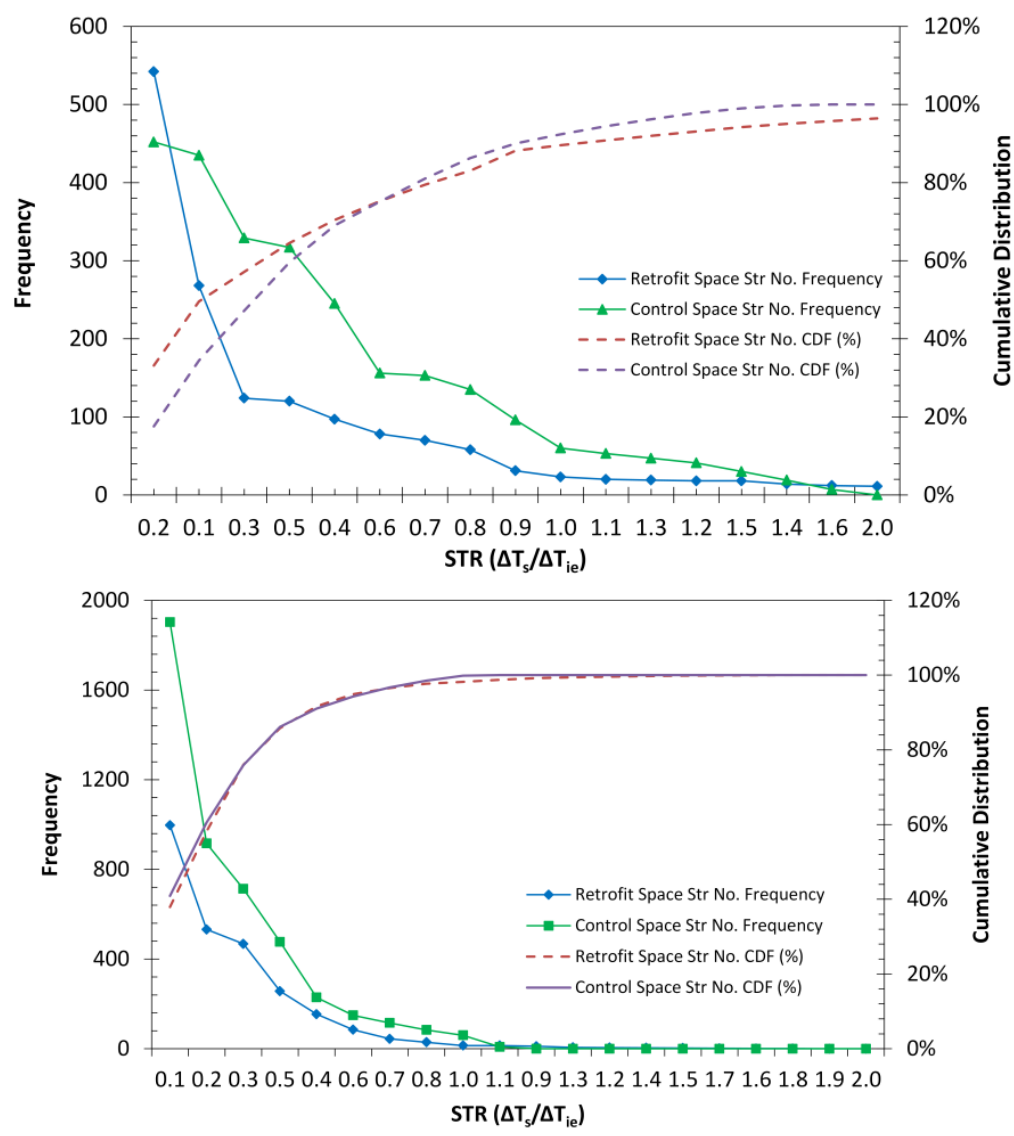

Figure 10: Frequency and cumulative distributions of $\mathbf{S T R}$ for control and retrofit spaces; (a) results for occupied hours (taken as 9am-6pm); (b) results for unoccupied hours.

\subsection{Zone air temperature time lag \& hrs of occurrence}

Tables 7 and 8 highlight longer term performance of internal environment of both spaces. Table 7 presents time of occurrence for maximum and minimum mid height air temperature values for a single week in July 2013 while Table 8 covers the hours of occurrence above certain threshold values.

Table 7: Measured $T_{\text {H/2(peak) }}$ Time Lag during week 8th-14th July 2013

\begin{tabular}{|c|c|c|c|c|c|c|c|c|c|c|}
\hline \multirow[b]{2}{*}{ Day } & \multicolumn{2}{|c|}{ External } & \multicolumn{4}{|c|}{ RS } & \multicolumn{4}{|c|}{ CS } \\
\hline & $\begin{array}{c}\text { Max } \\
\mathbf{T}_{\text {ext }} \\
\left({ }^{\circ} \mathbf{C}\right)\end{array}$ & $\begin{array}{l}\text { Occ. } \\
\text { (hr) }\end{array}$ & $\begin{array}{l}\text { Max } \\
\mathbf{T}_{\text {int }}\left({ }^{\circ} \mathbf{C}\right)\end{array}$ & $\begin{array}{l}\text { Occ. } \\
\text { (hr) }\end{array}$ & $\underset{\mathbf{T}_{\text {int }}}{\operatorname{Min}}\left({ }^{(} \mathbf{C}\right)$ & $\begin{array}{l}\text { Occ. } \\
\text { (hr) }\end{array}$ & $\begin{array}{l}\text { Max } \\
\mathbf{T}_{\text {int }} \\
\left({ }^{\circ} \mathbf{C}\right)\end{array}$ & $\begin{array}{l}\text { Occ. } \\
\text { (hr) }\end{array}$ & $\begin{array}{l}\text { Min } \\
\mathrm{T}_{\text {int }} \\
\left({ }^{\circ} \mathbf{C}\right)\end{array}$ & $\begin{array}{l}\text { Occ. } \\
\text { (hr) }\end{array}$ \\
\hline July $8^{\text {th }}$ & 25.4 & $16: 35$ & 29.0 & $18: 50$ & 24.4 & 06:00 & 36.8 & $19: 35$ & 25.0 & $05: 40$ \\
\hline July $9^{\text {th }}$ & 27.1 & $14: 40$ & 28.6 & $18: 40$ & 25.5 & $23: 40$ & 36.1 & $19: 00$ & 26.8 & 07:05 \\
\hline July $10^{\text {th }}$ & 26.4 & 13:00 & $29.1 *$ & 19:50 & 22.8 & $07: 10$ & 36.5 & $19: 25$ & 28.0 & $06: 10$ \\
\hline
\end{tabular}




\begin{tabular}{llllllllllc}
\hline July $11^{\text {th }}$ & 23.9 & $11: 45$ & $30.0^{*}$ & $18: 40$ & 22.8 & $06: 50$ & $-*$ & - & 25.0 & $07: 40$ \\
July $12^{\text {th }}$ & 26.4 & $15: 15$ & $28.0^{*}$ & $19: 00$ & 22.0 & $06: 30$ & $35.6^{*}$ & $17: 35$ & - & - \\
${\text { July } 13^{\text {th }}}^{\text {th }}$ & 27.8 & $14: 20$ & $28.4^{* *}$ & $18: 40$ & 25.1 & $06: 20$ & $36.1^{*}$ & $17: 45$ & 24.3 & $07: 45$ \\
July 14 & 25.8 & $16: 55$ & $27.9^{* *}$ & $20: 00$ & 25.8 & $07: 20$ & $33.9^{*}$ & $17: 20$ & 25.7 & $23: 40$ \\
\hline
\end{tabular}

*Denotes night cooling present the previous night using RS-4.0

** Denotes night cooling present the previous night using RS-3.0

Table 8: No of Hours above threshold values per month for Retrofit Space

\begin{tabular}{|c|c|c|c|}
\hline Retrofit Space & hrs $>23^{\circ} \mathrm{C}$ & hrs $>25^{\circ} \mathrm{C}$ & hrs $>28^{\circ} \mathrm{C}$ \\
\hline April & 4.2 & 0 & 0 \\
\hline May & 28.8 & 0 & 0 \\
\hline June & 195.5 & 26 & 0 \\
\hline July & 608 & 281.5 & 36.2 \\
\hline August & 218.5 & 0 & 0 \\
\hline September & 32.3 & 0 & 0 \\
\hline October & 46.3 & 0.5 & 0 \\
\hline
\end{tabular}

\section{CONCLUSIONS}

Experimental findings presented in this paper suggest that the retrofit works have modified both the internal thermal environment and mean ventilation rates during the cooling season for isolated spaces with single sided ventilation. The largest recorded ventilation rates in the retrofit space were, on average, still lower than the existing building under similar driving forces. Results indicate increased time varying ventilation rate fluctuations in the control space during testing compared with the retrofit space, suggesting an increased presence of unsteady air flow effects. The new louvred ventilation opening design in the refurbished building may be contributing to more stable instantaneous ventilation rates. Regarding Internal thermal environment, results suggest some properties have been modified with the mean zone air temperature substantially reduced. Diurnal internal air temperature amplitude has also been reduced. The retrofit space generally complied with category A of ISO7730 under vertical temperature difference criteria. $\Delta T_{s}$ had a lower magnitude in the retrofit space but had instances of higher STR values suggesting it had a higher relative strength compared to the existing building. Work continues on a detailed analysis of experimental results in terms of available correlations for single-sided ventilation.

\section{ACKNOWLEDGEMENTS}

The original pilot project works was supported through a grant from the Department of Education and Skills, Ireland. The authors wish to acknowledge the co-work of the pilot project design and research team in the design and development phases of the pilot project, Mr Fergus Delaney for providing the dynamic thermal response factors in Table 2, Mr Michael Murphy \& Mr Ger Rasmussen for technical assistance with instruments and Mr James Pittam for assistance with 3D imaging.

\section{References}

ASHRAE, 2009. ASHRAE Fundamentals, Atlanta: American Society of Heating, Refrigerating and Air Conditioning Engineers Inc.

ASTM, 2011. ASTM E741-11 Standard Test Method for Determining Air Change in a Single Zone by Means of a Tracer Gas Dilution. ASTM International, 00(2006), pp.1-18.

Caciolo M, Stabat P, and Marchio D, 2011. Full scale experimental study of single sided ventilation: Analysis of stack and wind effects. Energy \& Buildings, 43, pp. 1765-1773.

Caciolo M, Cui S, Stabat P, and Marchio D, 2013. Development of a new correlation for single-sided natural ventilation adapted to leeward conditions. Energy \& Buildings, 60, pp.372-382. 
Dascalaki E, Santamouris M, Argiriou A, Helmis C, Asimakopoulos DN, Papadopoulos K, Soilemes. On the combination of air velocity and flow measurements in single sided natural ventilation configurations. Energy and buildings 24.2 (1996): 155-165.

DCENR, 2013. Irelands Second National Energy Efficiency Action Plan to 2020, Dublin.

Etheridge, D., 2011. Natural Ventilation of Buildings: Theory, Measurement and Design, WileyBlackwell.

European Union, 2012. Directive 2012/27/EU on energy efficiency, amending Directives 2009/125/EC and 2010/30/EU and repealing Directives 2004/8/EC and 2006/32/EC. Official Journal of the European Union, (October), pp.1-56.

Knoll, B., Phaff, J. C., and de Gids, W. F. (1996) Pressure coefficient simulation program, in Air Infiltration Review, 17(3), 1-5.

Kolokotroni M, Kukadia V and Perera E, (1996) NATVENT - European project on overcoming technical barriers to low-energy natural ventilation, in Proc. CIBSE/ASHRAE Joint National Conference, Harrogate UK 1996, 29 September to 1 October, Volume I, pp36-41

Kolokotroni M and Warren P (2008), Building AdVent: Building Advanced Ventilation Technological examples to demonstrate materialised energy savings for acceptable indoor air quality and thermal comfort, Indoor Air 2008, Copenhagen, Denmark, August

Larsen, T.S. and Heiselberg, P., 2008. Single-sided natural ventilation driven by wind pressure and temperature difference. Energy and Buildings, 40(6), pp.1031-1040.

Li, Y., 2002. Integrating thermal stratification in natural and hybrid ventilation analysis, Hong Kong.

Meteonorm 7, Meteotest (www.meteonorm.com)

NSAI, 2006. IS EN ISO 7730:2006 - Ergonomics of the thermal environment - analytical determination and interpretation of thermal comfort using calculation of the pmv and ppd indices and local thermal comfort criteria

NSAI, 2007. ISEN 15251:2007 -Indoor Environmental Input Parameters for design and Assessment of Energy performance of Buildings addressing Indoor Air

NSAI, 2007. IS EN 13779:2007 - Ventilation for non-residential buildings - performance requirements for ventilation and room-conditioning systems.

NSAI, 2012. ISO 10077-2:2012 Thermal performance of windows doors and shutters - Calculation of thermal transmittance - Part 2 : Numerical method for frames.

O’Sullivan, P. Delaney, F. O'Riain, M. Clancy, T. O'Connell, J. and Fallon, D., 2013. Design and Performance of an External Building Envelope Retrofit Solution For a Grid Optimised Concrete Structure: A Case Study. In IMC30 Conference Proceedings 2013.

Persily, A., 1997. Evaluating Building IAQ and Ventilation with Indoor Carbon Dioxide. ASHRAE Transactions, 103, p.4072.

Roulet, C.-A., 2007. Ventilation and Airflow in Buildings: Methods for Diagnosis and Evaluation (BEST (Buildings, Energy and Solar Technology)), Routledge.

Seppänen, O., Fisk, W.J. and Lei, Q.H., 2006. Ventilation and performance in office work. Indoor air, 16(1), pp.28-36. 
Sherman, M., 1990. Tracer Gas Techniques for Measuring Ventilation in a Single Zone. Building and Environment, 25(4), pp.365-374.

Warren, P. R., and Parkins, L. M. (1985) "Single-sided ventilation through open windows." ASHRAE SP49, 209-228 